\title{
ESTUDIOS
}

\section{Linhas de fôrca na literatura brasileira}

Modernista na primeira metade do século 20 , a literatura brasileira alcança agora aquêle ponto de desenvolvimento orgânico e de vitalidade criadora que absorve o passado sem prolongá-lo e propõe, na sua com. plexidade caracteristica, uma premonição do futuro. Entre as sobrevivêtn. cias e as antecipações, é preciso distinguir as correntes subterrâneas que se cruzam: não se trata aqui de escolher as tendências que nos agradem ou pontos de vista que lisonjeiem as nossas inclinações, mas de fixar em linhas tanto quanto possivel nítidas a imagem fugidia de um momento histórico.

\section{TENDÊNCIAS ATUaIS}

Se aceitarmos a idéia de que o período modernista terminou em 1945 (data convencional e simbólica, como tôdas as da história literária), poderemos contar dêsse momento o início da literatura contemporânea", que ainda não conquistou o seu ismo particular, mas cujos caracteres principais podem ser fàcilmente percebidos.

A herança modernista, que foi, simultâneamente, realista e esteticista, subdividiu-se nas duas grandes correntes atuais, que contra ela reagem seja por prolongamento, seja por antítese. Com efeito, é curioso observar que a reação, já agora consciente, contra o Modernismo, faz-se com as próprias armas de combate por êle forjadas. O Modernismo, embora jamais o haja explicitamente admitido, procurou ser uma literatura realista pelo conteúdo e esteticista pela forma, além de ser, naturalmente, anti-acadêmica pelo espírito.

Dessas três "variáveis", a literatura contemporânea conservou, com a 
mesma intransigência, o anti-academismo, mesmo nos casos em que é realmente difícil distingui-lo das tendências estetizantes. Contudo, as duas outras se separaram nítidamente em duas correntes diversas. Escritores mais idosos, contemporâneos da fase atuante do Modernismo, preferem aparentemente rejeitar o esteticismo como forma de literatura acadêtnica e assumir sem constrangimento uma posição realista. Ainda que alguns jovens pareçam acompanhá-los nessa atitude, não se pode afirmar que ela dê o tom à literatura contemporânea, mais inclinada à chamada "pesquisa" literária, ao refinamento linguístico, à análise psicológica e à exploração das possibilidades exclusivamente estéticas da linguagem. No período modernista, apesar da alta dignidade que o, cscritores the atribuiam, a literatura ainda era um instrumento; nos dias atuais, ela se transformou na sua própria finalidade. Aceitemos sem despropositados temores e sem intenções polêmicas a palavra exata: o que define atualmente a literatura brasileira é uma volta sensível aos princípios da arte pela arte. Acrescentemos desde logo que essa posição só começa a ser censurável pelos seus excessos; enquanto ambição criadora ela é, sem contestação, das mais legítimas.

Nos anos 30 e 40, a palavra de ordem da literatura brasileira era o "compromisso", ou, como gostavam de repetir os que mais se deixavam influenciar pela terminologia francêsa, a "littérature engagée"; nos anos 50, inicia-se a reação estetizante que se prolonga até hoje. A literatura já não é encadeada, por definição, aos valôres "sociais" ou políticos, mas considera-se realizada na medida em que satisfaz às suas aspirações íntimas de criação ou de invenção puramente técnica.

\section{A) PROSA DE FICÇÃo}

Conforme tive acasião de escrever recentemente, ${ }^{1}$ "a linha do formalismo é a invisível fronteira que separa os escritores contemporâneos dos que já são, ou começam a ser, 'históricos', tanto na ficção e na poesia quanto na crítica e no ensaio: embora a crítica literária no Brasil tenha sido, nestes últimos anos, mais abstrusa do que realmente criadora de idéias teóricas e estéticas, mais afetada do que interpretativa, mais repleta de doutrinas do que rica em proposições iluminantes ou enriquecedoras, sempre é certo que, ela também, tem pôsto tôda a ênfase nos aspectos formais da obra de arte, na sua natureza de criação lingüística". Ao lado da crítica, a poesia tem sido, nas duas últimas décadas, essencialmente

1 Cf. Wilson Martins. "Tendências da Literatura Brasileira Contemporânea", Hispania, vol. XLVIII, n 3, setembro de 1965. 
formalista, até desembocar na corrente exasperadamente estetizante que é o Concretismo. Quanto à prosa, está vivendo um período simultâneo de formalismo e de realismo. Não mais o "realismo socialista" dos anos 30 (tão bem encarnado nos primeiros romances de Jorge Amado), mas o "realismo de escola", cujos predecessores são José Lins do Rêgo, Graciliano Ramos e Rachel de Queiroz. Em tentativas que não parecem ter despertado grande receptividade, alguns ficcionistas (mesmo e particularmente Jorge Amado, em certas produções menores) voltaram aos temas chamados "grosseiros", à observação minuciosa do mundo exterior, à visão pessimista do homem, à sátira ou à polêmica social, à linguagem direta e simples, aos palavrões escritos com tôdas as letras, ao interêsse pelo comportamento, ao desafio às convenções "burguêsas", e à intriga que é simbólica a seu modo, isto é, que propõe indiretamente um pro. grama de ação.

Pode-se pensar, entretanto, que essa corrente não é mais do que uma sobrevivência do Modernismo, por um lado, e, por outro lado, uma reação, talveź inconsciente, contra o esteticismo na prosa brasileira. $\mathrm{Na}$ verdade, a dominante seria lançada em 1946 por Guimarães Rosa, com a publicação de Sagarana, confirmada e extraordinàriamente fortalecida, dez anos depois, com o aparecimento de Grande Sertão: Veredas (1956). Ainda que, por sua espantosa originalidade literária, Guimarães Rosa haja fechado automàticamente tôdas as possibilidades de uma "escola" de romance que se desenvolvesse a partir de sua obra, devemos notar que êle próprio vinha inscrever-se numa tradição cujos primeiros sinais haviam surgido alguns anos antes com Perto do Coração Selvagem (1943), de Clarice Lispector. Quero dizer com isso que o formalismo de composição vinha substituir, na fiç̧ão brasileira, o estilo direto e jornalístico dos anos 20 e 30.

Foi tanta e de tal natureza a glória que ainda em vida cercou o nome de Guimarães Rosa que a sua morte, nas circunstâncias em que ocorreu, tomou todo o caráter de uma apoteose; apoteose que se prolongou, no plano editorial, desde o ano de 1968, com o aparecimento de dois volumes importantes que multiplicam as coincidências felizes e começam a fixar-lhe os traços definitivos à luz da eternidade literária. ${ }^{2}$ Como o basalto em que afinal se materializou o túmulo de Edgar Poe, Guimarães Rosa durante todos êstos anos aparecia, aos olhos de muitos, como um "calme bloc ici-bas chu d'un désastre obscur"; e não faltou quem afirmasse que êle também tinha vindo para "dar um sentido mais puro às palavras da

2 Mary Lou Daniel. João Guimarães Rosa: Travessia Literária; e Em Memória de Guimarães Rosa, Rio de Janeiro: José Olympio, 1968. 
tribo". Agora, a história intelectual retoma os seus direitos e, pelo simples fato de haver passado ao país da intemporalidade, êle se situa automàticamente numa tradição e pode ser visto em perspectivas que os mais argutos, de resto, não haviam ignorado.

Estudando o estilo de Guimarães Rosa do léxico à poética e da sintaxe à retórica, Mary Lou Daniel demonstrou-lhe claramente o "sistema", ainda que, malgrado o que sugeriam algumas análises anteriores, não tenha sido um sistema fixado de uma vez por tôdas em suas próprias limitações. Ao contrátio, até: Guimarães Rosa evoluiu, dentro de suas técnicas, abandonando direções que havia tomado nos primeiros volumes e adotando outras que êles não permitiriam pressupor (algumas das quais, alıas, repudiavam claramente os excessos retóricos da primeira fase). Assim, por exemplo, há "maior porcentagem de palavras brasileiras e zegionais em Sagarana do que nas outras obras do autor", porcentagem que decai de maneira regular até atingir o seu ponto mais baixo nas Primeiras Estórias. Em outras palavras, Guimarães Rosa evolui lèxicamente do regionalismo para o universalismo, obedecendo, de resto, à natureza profunda da sua própria visão literária e do seu estilo; se, a princípio, havia inventado o "regionalismo estético", o próptio impulsn adquirido o reconduz ao esteticismo pròpriamente dito. Nesse particular, Tutaméia, cuja essência "filosófica" não deixou de ser notada, confirmaria a justeza da observação e as sinclinais evidentes de todo o processo. Acresce que, mesmo nas obras mais carregadas de contingente regional, os "brasileirismos" eram três vêzes mais numerosos do que os "regionalismos", o que, naturalmente, só poderia ser percebido através da análise exaustiva de que Mary Lou Daniel deu o exemplo (nos dois sentidos da palavra). Ainda por ếsse lado, é incontestável a inclinação esteticista de Guimarães Rosa, autor que ergueu mais de uma armadilha a críticos por outros títulos tão estimáveis.

No capítulo final, em que resume as suas conclusões e propõe uma visão de conjunto do problema, Mary Lou Daniel escreve que Sagarana oferece, no seu léxico, "a maior porcentagem de brasileirismos; diminui esta em Corpo de Baile e Grande Sertão: Veredas, até atingir o seu ponto mais baixo nas Primeiras Estórias. Observa-se a mesma tendência decrescente no emprêgo do ritmo como técnica estilística. Desenvolvimento inverso, porém -o emprêgo cada vez mais intensivo- se nota mais comumente na sua obra: tais técnicas como a criação de palavras portmanteau e substantivos pós-verbais; o uso do imperfeito do subjuntivo numa variedade de funções; a anteposição de advérbios com relação aos seus verbos; o emprêgo de relativos ambivalentes no comêço das frases; e a 
função de construções gerundiais independentes". Outras técnicas manifestam tendência diversa, classificada pela autora como "padrão 'sobe-ebaixa"", isto é, aparecem em níveis de regularidade oscilante conforme os livros. Dentre elas, contam-se o emprêgo de -im como sufixo diminutivo generalizado e de $-a l$ e $-\tilde{a}$ na criação de neologismos, o uso extenso dos processos de aférese e encurtamento interno como uma espécie de 'fonologia do futuro', a troca reciproca na posição de artigos e adjetivos modificadores do mesmo substantivo, inversão geral de cláusulas, duplicação séria de várias categorias gramaticais, onomatopéia, e o emprêgo de anáfora e outros recursos retóricos. Êstes e outros aspectos do estilo de Guimarães Rosa aparecem com frequência reduzida ou moderada em $S_{a}$ garana, aumentam notávelmente em Corpo de Baile e Grande Sertão, e diminuem de igual maneira em Primeiras Estóriats".

Assim, as obras dos anos 50 revelam muito maior complexidade estilística do que as anteriores e posteriores. Vê-se bem que Guimarães Rosa começa, como todo o mundo, "experimentando" as suas possibilidades, embriaga-se momentâneamente com elas e as explora quase como uma finalidade $\mathrm{cm}$ si mesmas, para afinal chegar a um momento de sintese e equilibrio de que as Primeiras Estórias seriam a indicação inegável, conforme a seu tempo tive oportunidade de observar. A morte veio tolher e frustrar um nôvo processo dialético de que Tutaméia é, a meu ver, a tese, sem deixar de ser a síntese de ações e reações anteriores, ou uma evolução notmal, implícita na sua obra anterior. Seja como fôr, a exposição do "significado" que tiveram as experimentações lingüísticas de Guimarães Rosa revela, ainda uma vez, que o sentido do "literário" era nêle pelo menos tão dominante e intransigente quanto o sentido do "brasileiro"; e que, como todo criador autêntico, êle sabia que só poderia apresentar-se como litetatura o que como literatura tivesse sido imaginado e escrito. Tudo nêle é "artificial", neste sentido de que, ao contrário dos anos 30, nada é "sociológico"; mas é artificial como a própria arte, e o seu decálogo interior nada tinha de comum com o do romance brasileiro que o precedera.

Da mesma forma, embora êle próprio manifestasse escassas afinidades com os modernistas da primeira geração, e notadamente com Mário de Andrade, é certo que a sua obra não poderia ter existido sem a "liberação" espiritual que resultou da Semana de Atte Moderna. Mary Lou Daniel observa que o estilo de Guimarães Rosa vem "em linha direta da tradição dos Andrade", mas que, ao contrário do experimentalismo anárquico de Mário de Andrade, o de Guimarães Rosa é seletivo e previdente: "Podemos considerá-lo uma espécie de 'Mário depurado' que 
tira vantagem dos excessos e dos sucessos do seu predecessor". Não poderia ser melhor dito, pois Guimarães Rosa, a exemplo de tantos outros, que nada devem diretamente a Mário de Andrade, deve-lhe pelo menos isso: haver cometido os "erros" que êle próprio, por isso mesmo, já não precisaria mais cometer. Solicitado, com igual fôrça, pelas tendências contraditórias do "sociologismo" e do "esteticismo", o Movimento de 1922 foi esteticista nos seus primeiros momentos para sucumbir, a partir, digamos, de 1926, às tentações de uma literatura que era mais brasileira do que literatura. O próprio Mário de Andrade, como a sua argúcia ha. bitual, já podia escrevê-lo em 1931. Isso abre as portas para o "romance nordestino" e para a poesia política dos anos 30 e inícios da década de 40. Depois da guerra, e já em 1943, com Clarice Lispector, logo em seguida com Guimarães Rosa, em 1946, o pêndulo retoma a oscilação inver. sa, preparando o caminho para o nôvo esteticismo dos anos 50 (clímax da obra roseana) e 60 (com o Concretismo, por exemplo, mais pelo que significa do que pelo que foi, e em cujas fileiras se encontram, caracte. risticamente, alguns dos admiradores mais sistemáticos de Guimarães Rosa).

O estilo de Guimarães Rosa realizaria a síntese Modernismo-Antimodernismo de uma maneira sutil e inesperada: por um lado, aceitando sem falsa vergonha a natureza "literária" da literatura, e, por outro lado, mantendo a oralidade que foi, como se sabe, a expressão do estilo antiliterário dos modernistas entre 1922 e 1945 (esta última data, claro está, tem valor meramente indicativo). Assim, técnicas como a aliteração, a onomatopéia, a rima e o ritmo, que já são de si mesmas altamente esteticistas, juntam-se, na obra de Guimarães Rosa, à utilização não só consciente, mas sistemática, de recursos retóricos: "De fato", escreve Mary Lou Daniel, "não seria exagêro chamar de 'retórico' o seu estilo", o qua ela vê como um "paradoxo". O paradoxo, creio eu, será menos agressivo do que pareceria à primeira vista, se soubermos transpor as aparências em benefício das realidades profundas e das tendências dominantes. $\mathrm{O}$ estilo de Guimarães Rosa é "elegantemente bárbato", e muito menos "bárbaro" do que "elegante": tanto quanto o de Euclides da Cunha, êle pode enganar e propor ultracivilizadas trepadeiras ornamentais onde os Joaquim Nabuco só chegaram a ver grosseiras cordoalhas de cipó. Mas, sendo fundamentalmente retórico, isto é, "escrito" (e que só se pode realmente acompanhar com o texto à vista), o estilo de Guimarães Rosa é também oral (e só se pode compreender pela leitura em voz alta, para rão referir o fato de que, afinal, são histórias "contadas"). A maior parte da obra, escreve Mary Lou Daniel, "se compreende mais fàcilmente 
pelo ouvido que pelo ôlho". A anti-retórica dos modernistas era também essencialmente oral; a retórica de Guimarães Rosa será menos antimodernista do que se pensa (e do que êle próprio pensava).

No que se refere mais particularmente às técnicas romanescas, pode-se dizer que Guimarães Rosa procurou resolver à sua maneira o problema da aparência e realidade que, segundo Lionel Trilling, vem sendo, desde Cervantes, a tentativa essencial do romance. Sua obra situa-se, assim, nos domínios do romance experimental, a começar pelo que H. S. Reiss denomina a plurissignificância:

Os romances modernos comportam não apenas interpretação a níveis vátios; é também preciso interpretá-los em suas plurissignificações. Nem tanto porque uma sentença ou uma cena em particular, ou um tema, admita interpretações diferentes, mas antes porque algumas situações ou tramas coexistem sem qualquier ligação aparente, até que as afinidades ou associações sejam aos poucos percebidas e cada situação ou tema mostre, realmente, um entrosamento indiscutivel com tôdas as outras. Muitas vêzes isto é feito em experimentos com tempo e espaço. Joyce, por exemplo, usa ambos, ao fixar o espaço mediante a descrição de fatos múltiplos no tempo. Isso implica a técnica de montagem, tão bem conhecida de qualquer frequentador de cinema onde se empregam tomadas simultâneas, reduções de velocidade, atenuações de imagem, primeiros planos, vistas gerais e retrospeç̧ões. Mas Proust o faz evocando reminiscências através da associação de palavras e símbolos. Outra possibilidade é manter fixo o tempo enquanto acontecimentos múltiplos realizam-se no espaço. ${ }^{3}$

Daí o paradoxo característico do romance moderno: por um lado, a tendência à apresentação difusa, mas, por outro, o extremo rigor da planificação. Guimarães Rosa acentuou em pelo menos cinco lugares diversos do Grande Sertão o que o processo tsm de deliberado e consciente; a narrativa se desenvolve não na ordem cronológica indiferente, mas segundo o que se poderia denominar o calendário sentimental:

O que vale, são outras coisas. A lembrança da vida da gente se guarda em trechos diversos, cada um com seu signo e sentimento,

3 "Style and Structure in Modern Experimental Fiction", in Stil- und Formprobleme in der Literatur. Vorträge des VII. Kongresses der Internationale Vereiningung für modern Sprachen und Literaturen in Heidelberg. Heidelberg: Carl Winter Universitätsverlag, 1959, p. 422. 
uns com os outros acho que nem não misturam. Contar sêguido, alinhavado, só mesmo sendo as coisas de rasa importância. De cada vivimento que eu real tive, de alegria forte ou pesar, cada vez daquela hoje vejo que eu era como se fôsse diferente pessoa. Sucedido desgovernado. Assim eu acho, assim é que eu conto. O senhor é bondoso de me ouvir. Tem horas antigas que ficaram muito mais perto da gente do que outras, de recente data.

Haveria, assim, ao lado de um "perspectivismo lingüístico", já estudado por Leo Spitzer com relação ao Quixote, um "perspectivismo estrutural" (que acorre em todo romance experimental e, de resto, em todo grande romance), cuja síntese seria a cristalização da obra enquanto obra de literatura. Ao lado dessa técnica, Guimarães Roa foi um alerta praticante do que o mesmo Leo Spitzer denominava a polionomásia. $O$ processo que consiste em dar aos personagens nomes "significativos", seja com vista a efeitos humorísticos, seja como recurso de caracterização, não é nôvo em literatura, nem tem relações diretas com a questão que nos preocupa. J. B. Rudnyckyi, estudando as funções do nome próprio na obra literária," lembra que em Gogol, por exemplo, um nome próptio "significativo" substitui uma longa descrição da pessoa e serve de base para a criação imaginária da figura no espírito do leitor. As sim, Taras Bul'ba adquire desde logo uma configuração sólida já que bul'ba significa batata. Tchecov, igualmente utilizava nomes próprios que insinuassem desde logo alguma coisa sôbre o carácter do figurante. Outros, já ertudaram as implicações humorísticas que se contêm em certos nomes no romance de Dostoievski. No que se refere a Guimarães Roa, o modêlo mais claro do processo é o nome do alemão Wusp:

Pois ia me esquecendo: o Vups! (...) Ah, o senhor conheceu êle? O titiquinha de mundo! E como é mesmo que o senhor frasêia? Wusp? E. Seo Emílio Wuspes... Wúpsis... Vupses. Pois êsse Vupes apareceu lá...

A mesma técnica é empregada com relação a todos os nomes, conforme será fácil verificar: assim, um nome nobre como José Rebêlo Adro Antunes transforma-se em Zé Bebelo, com o que se satisfazem ao mesmo tempo os dois gostos típicos das classes populares brasileiras: o nomes longos e os apelidos significantes. Manoel Inácio será "Malinácio dito"; e o nosso Carlos Magno, o solene José Otávio Ramiro Bettancourt Ma-

4 Stil- und Formprobleme in der Literatur, cit., p. 378 e ss. 
rins, seria, mais familiarmente, isto é, afetivamente mais próximo, Joca Ramiro. Enfim, a bela Maria Deodorina da Fé Bettancourt Marins, asšim batizada em honra do Marechal Deodoro, passa pela polionomásia em diversos planos: como Diadorim, muda de sexo e de caráter; adquirindo as aparências de homem, aproxima-se ainda mais do patronímico; reduzindo-se ao diminutivo de afeição, reduz-se às proporções humanas $e$ cotidianas do grupo; passando de Maria Deodorina a Diadorim, e depois de Diadorim a Maria Deodorina, representa de maneira concreta a natureza versátil da realidade; finalmente, enquanto Reinaldo, assumia, pelas evocações fonéticas e morfológicas, as espécies do cavaleiro medieval. Que o processo é consciente, prova-se pelo axioma de corpo de Baile: "Ali no sertão, atribuiam valor aos nomes, o nome se repassava do espírito e do destino da pessoa, por meio do nome produziam sortilégios".

Estabelecidos êsses antecedentes, compreenderemos melhor o aparecimento do "nôvo romance" brasileiro, nos anos 50. O livro de Jorge Amado, Gabriela, Cravo e Canela, em 1958, foi uma brilhante sintese entre as duas tendências, mas afirmava, na verdade, o predomínio do esteticismo pois significava, de parte dêle, o repúdio do "realismo socialista", já insinuado com a composição antetior de Velbos Marinheiros (publicado em volume em 1962). É nítida, nessa evolução global, a passagem para o romance urbano, contràriamente às inclinações rurais que haviam predominado no período precedente. Caso igualmente exemplar é o de Marques Rebêlo que, com O Espelho Partido (1959), cría uma obra extremamente original e comparável, tanto nas tendências quanto na qualidade, às de Guimarães Rosa e Jorge Amado. Se, com Maria Alice Barroso e alguns jovens ficcionistas, geralmente publicados pela Editôra GRD, do Rio de Janeiro, o "nôvo romance" fêz a sưa entrada na literatura brasileira, Marques Rebêlo, segundo observei alhures, pode ser visto como uma espécie de mestre mais idoso dêsse grupo. Nem todos os "novos romances" são da mesma qualidade e a qualidade de muitos pode ser contestada. Contudo, Maria Alice Barroso, com História de um Casamento (1960), Gerardo de Melo Mourão, com O Valete de Espadas, no mesmo ano, Olympio Monat, com Um Homem Sem Rosto (1964) e C. O. Louzada Filho, com Dardará (1965) propuseram uma renovação formal da prosa e das técnicas de ficção em tudo comparável à que paralelamente se verifica na poesia.

No polo històricamente oposto ao dêsses romancistas, situam-se alguns grandes mestres do período anterior. Um dêles, Aníbal Machado (1894-1964), gozou de extraordinátria reputaçãa mesmo anțes de sụa 
estréia em livro, o que sòmente viria a ocorrer em 1946, com Vila Feliz. João Ternura (1965), o romance quase mítico em que trabalhou durante a vida inteira, e que provocara entusiasmo mesmo antes de ser conhecido, viria a surgir pòstumamente. Cyro dos Anjos, que alcançara celebridade anteriormente, com $O$ Amanuense Belmiro (1936), voltaria, em 1945, com Abdias, e em 1956 com Montanba. Octavio de Faria continuaria, também, a séric famosa da Tragédia Burguesa, que, despertando igualmente grandes entusiasmos e sérias restrições, ficará, de qualquer modo, como o grande romance católico da literatura brasileira. O caso de Érico Veríssimo é ainda mais significativo, pois, havendo estreado em 1933, é em 1948 que começa a publicar a sua obra-prima, O Tempo e o Vento, destinada a tornar-se um dos grandes monumentos da ficção brasileira moderna. Todo êsse grupo, bem entendido, ou prolonga, já um pouco anacrônicamente, o "estilo" da ficção modernista (como Aníbal Machado) ou representa orientações que sempre se mantiveram independentes das disputas de escola, como Octavio de Faria, Cyro dos Anjos e Érico Veríssimo. Mas, com isso, e afirmando, indubitàvelmente, uma concepção exclusivamente literária e psicológica da literatura, êles podem ser vistos como os autores indispensáveis que prepararam a transição para as técnicas estetizantes dos nossos dias.

Tanto quanto Guimarães Rosa, Mário Palmério, autor de Vila dos Confins (1956) e Chapadão do Bugre (1965), é, não sòmente um dos dois ou três ficcionistas brasileiros mais importantes e criadores, como, também, um renovador do gênero. Tendo escrito duas obras-primas do romance moderno, sua arte pode ser tida como uma conciliação entre o regionalismo da fase modernista e o esteticismo da fase pós-modernista. Em outras palavras, êle, como Guimarães Rosa, trata os temas regionalistas como temas de literatura, e não como temas de sociología (mesmo fictícia). É igualmente o caso de José Cândido de Carvalho que, com O Coronel e o Lobisomem (1964), elevou ao plano da grande literatura universal alguns dos temas "regionalistas" que haviam caracterizado as letras brasileiras nos anos 30 . Vê-se, pois, que um nítido processo de síntese se opera na literatura brasileira, através de obras à primeira vista tão díspares e distantes entre si quanto as de Clarice Lispector, Guimarães Rosa, Jorge Amado (o Jorge Amado posterior a 1958) e Mário Palmério, síntese que, com os autores mais jovens do "nôvo romance", já ses estáa consțituindo em nova tese a ser proposta para o futuro. 
B) PoEsia

Mas, parece indiscutível que o aspecto mais saliente da renovação literária no Brasil, aquêle com que a "vanguarda" mais se identifica, manifesta-se na poesia. A essas palavras, com que, no citado artigo de Hispania, apresentei as tendências da literatura brasileira contemporânea, deve-se acrescentar que as revoluções poéticas dêstes últimos anos correspondem, ponto por ponto, a movimento semelhante na prosa, de acôrdo com os caracteres acima expostos. Em 1957, consolidando pela primeira vez os princípios implícitos da poesia concreta (que então ainda se escrevia entre aspas e ainda não havia adquirido o "ismo" que a transformou em movimento literário), Augusto de Campos, que é um dos seus teóricos, doutrinava:

- a poesia concreta começa por assumir uma responsabilidade total perante a linguagem: aceitando o pressuposto do idioma histórico como núcleo indispensável de comunicação, recusa-se a absorver as palavras como meros veículos indiferentes, sem vida sem personalidade sem história túmulos-tabus com que a convenção insiste em sepultar a idéia.

-o poeta concreto não volta a face às palavras, não thes lança olhares oblîquos; vai direto ao seu centro, para viver e vivificar a sua facticidade.

- o poeta concreto vê a palavra em si mesma — campo magnético de possibilidades - como um objeto dinâmico, uma célula viva, um organismo completo, com propriedades psico-físico-químicas, tacto antenas circulação coração: viva.

- longe de procurar evadir-se da realidade ou iludi-la, pretende a poesia concreta, contra a introspeç̧ão autodebilitante e contra o realismo simplista e simplório, situar-se de frente para as coisar, aberta, em posição de realismo absoluto.

-o velho alicerce formal e silogístico-discursivo, fortemente abalado no comêço do século, voltou a servir de escora às ruinas de uma poética comprometida, híbrido anacrônico de coração atômico e couraça medicval.

- contra a organização sintáxica perspectivista, onde as palavras vêm sentar-se como "cadáveres em banquete", a poesia concreta opõe um nôvo sentido de estrutura, capaz de, no momento histórico, captar, sem desgaste ou regressão, o cerne da experiência humana poetizável. 
-mallarmé ("un coup de dés" - 1897), joyce ("finnegans wake") pound ("cantos" - ideograma), cummings, e num segundo plano apollinaire ("calligrammes") e as tentativas experimentais futuristas-dadaistas, estão na raiz do nôvo procedimento poético que tende a impor-se à organização convencional cuja unidade formal é o verso (livre inclusive).

-o poema concreto ou ideograma passa a ser um campo relacional de funções.

-o núcleo poético é pôsto em evidência não mais pelo encadeamento sucessivo e linear de versos, mas por sistema de relações e equilibrios entre quaisquer partes do poema.

-funções-relações gráfico-fonéticas ("fatôtes de proximidade e semelhança") e o uso substantivo do espaço como elemento de composição entretêm uma dialética simultânea de ôlho e fôlego, que, aliada à síntese ideogrâmica do significado, cria uma totalidade sensível "verbivocovisual", de modo a justapor palavras e experiência num estreito colamento fenomenológico, antes impossível.

-POESIA CONCRETA: TENSÃO DE PALAVRAS-COISAS NO ESPAÇO-TEMPO.

Pouco tempo depois, no primeiro trimestre de 1962, a revista $1 n$ venção, que é o órgão oficial do Concretismo, publicava, no seu número inaugural, o "Plano-piloto para Poesia Concreta", datado de 1958 e assinado pela trilogia já agora histórica dos seus tratadistas (Augusto de Campos, Décio Pignatari e Haroldo de Campos). ${ }^{5}$ Depois disso, os próprios Concretistas resolveram superar-se a si mesmos e propuseram, no Congresso de Crítica e História Literária de Assis, em 1961, um retôrno ao "conteudismo", de resto jamais realizado, e, mais tarde, considerando aparentemente esgotadas essas duas fases, uma poesia fundada na teoria da comunicação ou semiótica, isto é, conforme afirma literalmente Décio Pignatari, na tentativa de desenvolver o desenho, gráfico e industrial, como forma de linguagem:

From 1961 on, concrete poets face definitely the "engagement" question. What issued - social and political concrete poetry- was chiefly based on Mayakovsky: "There is no revolutionary art without revolutionary form."

\footnotetext{
5 Para o texto dêsse manifesto e exemplos de poesia concretista, v, o já cițado $n^{9}$ de Hispaniat.
} 
Today: diversified trends and tendencies within the group, some worrying more about semantic and permutational features of the language. (Augusto \& Haroldo de Campos, this one also interested in prose problems), some turned to the creation of new langua. ges-even before and/or beyond the word-in poetry as well in prose, as far as a text can be so divided. ${ }^{6}$

Paralelamente ao Concrctismo, desenvolveu-se o movimento da Poesia-praxis, invenção de Mário Chamie, que o lançou, em 1961, com o livro Lavra Lavra. É a êsse grupo que pertence o romancista C. O. Louzada Filho, anteriormente citado. Que é o poema-praxis? Segundo o "manifesto didático" de Mário Chamie, "é o que organiza e monta, estèticamente, uma realidade situada, segunido três condições de ação: a) 0 ato de compor; b) a área de levantamento da composição; c) o ato de consumir".

Como entrosar essas correntes no desdobramento histórico da literatura brasileira contemporânea? Terão os poetas, como os prosadores, pontos evidentes de articulação com as fases anteriores? Tais pontos de contacto existem, porque a "nova poesia" é, no fundo, um retôrno às tendências estetizantes do Modernismo, da mesma forma por que a sua aceitação do "engagement" é outro retôrno, desta vez à literatura comprometida da década de 30. Na verdade, conforme acentuei no já citado artigo de Hispania, a grande influência sôbre os concretistas (que a admitem) como sôbre os praxistas (que já começam a admiti-la) parece a do poeta João Cabral de Melo Neto, cuyo volume Duas Águas (1956) poderá vir a ser, futuramente, um dos marcos históricos da poesia moderna no Brasil. Cabral situa-se originalmente no ponto de intersecção da poesia modernista com a poesia pós-modernista: digamos, mais precisamente, que êle parecia destinado a assegurar a sucessão de Carlos Drummond de Andrade, assim como êste representou a evolução da poesia pròpriamente modernista para a poética dos anos 30 e 40. João Cabral e Jorge de Lima seriam os dois nomes a guardar para uma análise, hoje mais necessária do que nunca, que tentasse explicar a decidida tendência formalista que, em determinado momento, repudiou a inclinação social ou sociológica, se não puramente pitoresca e humorística, da década de 20.

E bem possível que, reveladas tais correntes profundas, as revoluções

${ }^{6}$ Cf. Décio Pignatari. "The Concrete Poets of Brazil", The Times Literary Supplement, setembro 3, 1964, p. 791. Boa análise dos programas e realizaçóes do grupo concretista é a de Luciana Stegagno Picchio, "Crisi del Linguaggio e Avanguardie Letterarie in Brasile", estratto della Rivista Paragone, no 190. Milano: Mondadori, s. d. (1965?) 
posteriores pareçam menos revolucionárias e, talvez, menos duradouras; da mesma forma, a exemplo do próprio João Cabral, por um lado, e de Ferreira Gullar, por outro (que lançou, em 1954, A Luta Corporal, primeiro volume de poesia concretista), a vanguarda talvez se destine a um certo recuo tático e estratégico. Com efeito, a febril atividade dos concretistas, revelada através da publicação sucessiva e cada vez mais frequente de novos "manifestos", tanto pode ser sintoma de uma extraordinária capacidade de invenção quanto de uma insatisfação evidente com os resultados até agora obtidos. A Invenção de Orfeu, de Jorge de Lima, em 1952, foi a tentativa mais audaciosa de retôrno ao esteticismo puro no interior do Modernismo ou do que pode ser considerado uma sobrevivência do Modernismo. Essa "volta a Camões" representa, também, a confissão expressiva de que o Modernismo não havia cumprido tôdas as suas promessas e de que já era tempo de regressar à literatura "lite. rària".

\section{C) CRÍticA LITERÁRIA}

Os mesmos debates, as mesmas preocupações e, afinal, as mesmas tendências podem ser igualmente observados no que se refere à crítica literária -o que, completando a "fisionomia" das letras brasileiras contemporâneas, mostra-lhes o desenvolvimento orgânico, complexo e coerente a que aludi nas linhas iniciais.

A década de 50, tomada em conjunto (isto é, desde os fins dos anos 40 até aos princípios dos anos 60) foi dominada pelo debate a respeito dos métodos e princípios da crítica literária. Essa literatura, limitada a um aspecto restrito e quase "profissional" da inteligência, encontra expressão característica no livro de Afrânio Coutinho, Correntes Cruzadar, em 1952; no desdobramento natural das suas perspectivas e dos pontos de vista desde então afirmados por um grupo de críticos brasileiros, podemos mencionar Oswaldino Marques e o Laboratório Poético de Cassiano Ricardo (1962); Fantasia Exata (1959), de Franklin de Oliveira; A Luta Literária (1961), de Fausto Cunha; Cronistas do Absurdo (1964), de Léo Gilson Ribeiro; Razão do Poema (1965), de José Guilherme Merquior e, finalmente, A Sereia e o Desconfiado (1965), de Roberto Schwarz.

Embora nem todos os "jovens críticos" sejam "novos críticos", no sentido especializado da expressão, é inegável a influência exercida por Afrânio Coutinho na divulgação do "new criticisma?" e jdéias correlatas, 
Em 1964, êle sintetizou em oito pontos as "idéias fundamentais que integram o arcabouço do movimento renovador":

1) Necessidade da criação de uma consciência crítica para a literatura brasileira, a fim de corrigir a atitude acrítica e empírica na criação e no exercício da literatura;

2) Valorização do estudo superior e sistemático de letras nas Faculdades de Filosofia, instrumento dessa criação da consciência crítica;

3) Reconsideração dos problemas técnicos da poesia, ficção e drama, graças ao mesmo estudo superior, e, ao mesmo tempo, criação do espírito profissional e de especialização na crítica;

4) Defesa da perspectiva e abordagem estético-literária na apresentação crítica, contra o predomínio do método histórico, embor.a sem o abandono das contribuições históricas, mas colocando-as no seu lugar de subsídio, quando úteis à compreensão da obra:

5) Valorização da concepção estética da crítica, para a qual o que importa, sobretudo, é a obra, o texto, e na análise do texto - de poesia ou prosa- criar métodos que visem a penetrar-lhe até o núcleo intrínseco, ou essência estética da obra de arte literária, métodos êstes intrínsecos ou ergocêntricos em oposição aos extrinsecos;

6) Estabelecimento de critérios críticos de cunho objetivo, "científicos", isto é, critérios que absorvam cada vez mais o espírito científico, introduzindo em seus domínios as revoluções metodológica e científica que lograram outras disciplinas, e o rigorismo metodológico característico do espírito científico e das disciplinas que seguem o raciocínio lógico-formal. Mas sem recorrer aos métodos das várias ciências, e sim procurando desenvolver métodos peculiares ao objeto de estudo da crítica literária (o fato literário), ou rétodos literários, "poéticos", estéticos;

7) Relegação para segundo plano da preocupação biográfica em crítica; o mesmo em relação aos fatôres ambientais, históricos, sociológicos, econômicos, supervalorizados pelo determinismo naturalista;

8) Revisão dos conceitos historiográficos, à luz dêsses princípios, com a criação de nova teoria historiogtáfica para a literatura, que ponha em relêvo o fenômeno literạ́rio em sua autonomia, e 
crie um sistema de periodização de natureza estética e pelos estilos individuais e de época. ${ }^{7}$

São, como se vê, os princípios preconizados, de forma geral, pelo "new criticism" e correntes assimiladas, tôdas elas inscritas no mesmo esfôrço de análise puramente estética ou estilística da obra de arte literária que vem dominando a crítica dêstes últimos anos em todos os países do mundo. O próprio Afrânio Coutinho admite que as suas idéias resultaram de influências recebidas nos Estados Unidos, de onde regressou para o Brasil em 1948. Como "exemplo mais frisante e indiscutível" dos novos métodos de aproximação literária, êle aponta $A$ Literatura no Brasil, obra que concebeu e planejou desde 1951 e que se vem publicando desde 1955. Para utilizar as suas próprias palavras, êsse livro se caracteriza por

um princípio diretor de natureza estética que é conceito estético ou poético da literatura, literatura concebida como arte, a arte da palavra, produto da imaginação criadora, com valor e finalidade em si mesma, dotada de composição específica e elementos intrínsecos; a crítica como análise dêsses componentes específicos ou estéticos; a his. tória literária como história dessa arte no seu desenvolvimento autônomo; a libertação da literatura de sua subordinação ao histórico, à cronologia, à biografia; o primado da obra como norma de crítica; a redução dos gêneros literários aos de específica natureza literíria (romance, conto, poesia, drama, crônica, epopéia, etc.); a adoção da periodização estilística fundamentada nas noções de estilo individual e de estilo de época, com o estudo da literatura brasileira à luz de uma reformulação dos períodos, em barroquismo, neoclassicismo, arcadismo, romantismo, realismo, naturalismo, parnasianismo, simbolismo, impressionismo, modernismo, do que resultou a revisão e clarificação de pontos duvidosos, obras e figuras não classificadas ou mal interpretadas, como a origem da literatura brasileira, Anchieta, Vieira, o barroco literário brasileiro, o impressionimo na literatura, Raul Pompéia, Graça Aranha, etc. ${ }^{8}$

Essas foram as intenções e o programa de $A$ Literatura no Brasil. Afrânio Coutinho reconhoce que, dada a diversidade de colaboradores a que teve de recorrer, nem todos responderam completamente -as suas ex-

7 Afrânio Coutinho. "A Crítica Literária no Brasil", Inter-Amevican Review of Bibliography, vol. XIV, $\mathrm{n}^{\circ} 2$, April-June 1964, 137.

op. e lor, cit, pp. 143-144. 
pectativas e ao rigor metodológico preconizado. É certo, porém, que essa obra marca, mais do que Correntes Cruzadds, uma data importante na historiografia literária do Brasil.

Evoluindo, ao longo do período, da crítica sociológica para a crítica estruturalista, a obra de Antônio Cândido of erece um exemplo de desemvolvimento de uma crítica estética sem os excessos sistemáticos e polêmicos de Afrânio Coutinho. Iniciada em 1943 com uma tese universitária sôbre o método crítico de Sílvio Romero e levada até 1965 com uma coletânea de ensaios sốbre a concepção sociológica da literatura (Literatura e Sociedade), a obra de Antônio Cândido encontrou o seu coroamento indiscutível com o livro, hoje clássico, Formação da Literatura Brasileira (1959). Essa obra é importantíssima, não apenas porque renova inteiramente a visão histórica das nossas letras entre o século 18 e o século 20 , mas ainda porque harmoniza sutilmente os dois elementos que a Afrânio Coutinho parecem inconciliáveis ou recíprocamente hostis: o histórico e o estético.

Antônio Cândido, como eu próprio, tenderia a uma utilização das diversas possibilidades metodológicas de acôrdo com o tipo de problema crítico ou historiográfico a resolver. Com ef eito, em comunicações ao II Congresso Brasileiro de Crítica e História Literária (Assis, São Paulo, 1961) e ao IX Congresso Internacional da Federação Internacional de Linguas e Literaturas Modernas (New York, 1963), tive oportunidade de propor a visão da crítica como uma síntese tríplice e simultânea.

Segundo essa concepção, tanto o monismo quanto o ecletismo são falsas proposições do problema crítico. A meditação metodológica é de natureza lógica e não estética, é um esfôrço lógico aplicado a uma realidade estética (a obra literária), como pode ser aplicado a uma ciência, sem que por isso seja científico, ou a uma arte, sem que se torne artístico. Assim, os diversos métodos não se exclucm, mas completam-se e complementam-se entre si numa sintese ideal que não se confunde com o ecletismo imediatista nem com qualquer impossivel "mistura" de métodos. A sintese metodológica só se completa no plano filosófico e corresponde a uma escala de contribuição prioritária, já que cada problema crítico implica a adoção preferencial de um método determinado.

Filosòficamente, o ponto central dessas comunicações pretende que não existe nenhuma crítica literária em si mesma: a crítica é sempre a crítica de alguma coisa, é a tentativa de solução de um problema concreto. Exatamente por isso, não há metodologia em abstrato. Por outro lado, considerando que a literatura só tem sentido no interior de um quadro de nação, civilização e momento histórico, a crítica deve tender a ser uma síntese 
suprema que veja a criação literária em suas verdadeiras perspectivas, não sòmente técnicas, mas também intelectuais e humanas.

Em conclusão, a crítica literária, considerada em sua natureza profunda, implica a tentativa de estabelecimento de três sinteses simultâneas (das quais o ensaio crítico, por sua vez, é a síntese literária ou interpretativa):

1) a síntese dialética entre a tese da obra e a antítese do julgamento;

2) a sintese metodológica, fundada na utilização prioritàriamente decrescente de tôdas as técnicas de estudo, segundo o plano específico do problema crítico a resolver (biográfico, genérico, estilístico, histórico, etc.);

3) a síntese bistórica, no sentido mais largo da expressão, que inscreva a literatura nos seus quadros próprios de nação, civilização $e$ momento histórico. ${ }^{9}$

Vê-se que tanto os gêneros chamados "criadores" quanto a crítica li. terária estão realizando a obra comum de síntese entre o nacionalismo modernista e o cosmopolitismo estético. Êsse movimento é simultâneo e, em grande parte, a consequência, do estatuto universal adquirido pelas letras brasileiras nestes últimos anos.

New York University

Wilson Martins

9 Cf. Wilson Martins. "La Critique comme Synthèse", Literary History and Literary Criticism. Acta of the Ninth Congress, International Federation for Modern Language and Literature. New York: New York University Press, 1965, p. 232. Cf. igualmente Anais do Segundo Congresso Brasileiro de Crítica e História Literária. Assis, 24-30 de julho de 1961. Assis: Faculdade de Filosofia, Ciências e Letras, 1963, p. 139 e s. 